\title{
Mattew Mac Namara, La Textualisation de Madame
}

\section{Bovary}

\section{Isabella Giovinazzo}

\section{(2) OpenEdition}

1 Journals

\section{Edizione digitale}

URL: https://journals.openedition.org/studifrancesi/41007

DOI: 10.4000/studifrancesi.41007

ISSN: 2421-5856

\section{Editore}

Rosenberg \& Sellier

\section{Edizione cartacea}

Data di pubblicazione: 1 juillet 2004

Paginazione: 214

ISSN: 0039-2944

\section{Notizia bibliografica digitale}

Isabella Giovinazzo, «Mattew Mac Namara, La Textualisation de Madame Bovary», Studi Francesi

[Online], 142 (XLVIII | I) | 2004, online dal 30 novembre 2015, consultato il 09 septembre 2021. URL: http://journals.openedition.org/studifrancesi/41007; DOI: https://doi.org/10.4000/studifrancesi. 41007

Questo documento è stato generato automaticamente il 9 septembre 2021.

\section{(c) 9 (i) $\Theta$}

Studi Francesi è distribuita con Licenza Creative Commons Attribuzione - Non commerciale - Non opere derivate 4.0 Internazionale. 


\title{
Mattew Mac Namara, La Textualisation de Madame Bovary
}

\author{
Isabella Giovinazzo
}

\section{NOTIZIA}

MATTEW MAC NAMARA, La Textualisation de Madame Bovary, Collection Faux titres n.233,

Rodopi, Amsterdam - New York 2003, pp. 263.

1 L'autore del presente volume, che rientra nel vasto ambito critico dell'analisi della testualizzazione dell'opera Flaubertiana, propone qui la trascrizione di sessantadue tra le oltre tremila e seicento pagine di brouillon di Madame Bovary, e di dieci pagine del manoscritto autografo del romanzo, che non costituiscono altro che l'avantesto del capitolo quindicesimo della seconda parte del romanzo, per mettere in evidenza i processi di testualizzazione messi in opera dall'autore nella composizione del testo, la genesi e la formazione progressiva della scrittura.

2 I testi trascritti sono presentati in tre serie successive, che costituiscono le tappe di composizione di ogni pagina, ricostruite sulla base di dati testuali interni alle pagine stesse, ovviamente messi in chiara evidenza dal critico a giustificazione dell'organizzazione proposta. Per ognuna delle pagine presentate vengono analizzati il rapporto testuale con la precedente e la successiva; l'espansione o la riduzione del suo spazio, della formazione di sintagmi, proposizioni e paragrafi, tanto dal punto di vista concettuale che grafico, la ricorrenza di parole chiave o figure di stile. A conclusione del lavoro, l'autore cerca di mettere in evidenza le implicazioni comunicative delle peculiarità della testualizzazione flaubertiana, anche in rapporto alle convenzioni mimetiche della narrazione realista francese della fine del XIX secolo, all'interno della quale Flaubert si distingue anche in virtù del suo lavoro di testualizzazione. 